\begin{tabular}{|c|c|}
\hline & $\begin{array}{l}\text { International Journal of Trend in Scientific } \\
\text { Research and Development (IJTSRD) }\end{array}$ \\
\hline 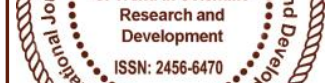 & International Open Access Journal \\
\hline & ISSN No: 2456 - 6470 | www.ijtsrd.com | Volume - 2 | Issue - 2 \\
\hline
\end{tabular}

\title{
Cloud Accounting - It's Benefits and Challenges
}

\author{
Prof. Piyush. M. Modi \\ Lecturer in Accountancy, Sheth C.D.Barfiwala \\ College of Commerce, Surat, India
}

\begin{abstract}
Cloud accounting refers to transactions performed over the internet. The practice does not require you to install software in your computer or own a server. A cloud computing company that sells accounting services provides remote servers and the applications. It is simply using the internet to access software and storage rather than physically installing it in a computer. Cloud accounting is also known as "online accounting" serves the same function as cloud computing. We have to install only the software on our computer but it runs on servers and we can access it using our internet. In some instances, we would not need to install the software on our computer and can access it via web browser. Technological trend of recent years brings forward the concept of cloud computing an innovative model of processing and storage of data that allows companies to run business smoothly. The study has made an attempt to find out the benefits and issues of cloud accounting an accounting and decision making abilities of the firm. The benefits are more in compared to the issues involved in using cloud based accounting system. This paper focuses on the impact of cloud accounting on each factor in the entire business area.

cash flow. Working on the cloud will give us the opportunity to reduce the amount of time that we spend working on tedious, time-consuming tasks, allowing us to concentrate on what we do best: growing your business. We can also be confident that we will have greater access to real-time data for our business - no matter where we are - as business information is accessible any time, any place, on any device that has internet access. Cloud accounting is the use of online accounting software where our data and software are stored on the internet, rather than on our computer hard drive. It can be accessed at any time in any place from any device that has internet access. Cloud accounting software is similar to desktop accounting software but it is hosted as remote servers i.e."In the Cloud". Users access the software applications remotely through the internet. Data is also started in the cloud which means it can be accessed from anywhere on any device with an Internet connection. Most cloud accounting providers use software as a service business model and subscriptions are usage based. The provider completes data back-ups and up-dates the software automatically.
\end{abstract}

Keywords: Cloud Accounting, Cloud Computing, Risks and Benefits

\section{INTRODUCTION:}

Running a successful small business usually means that we are focused on looking after our customers, growing sales and improving profitability. It also means that we are on top of our finances with up todate, accurate information, so that we can make wellinformed decisions, improve profits and manage your

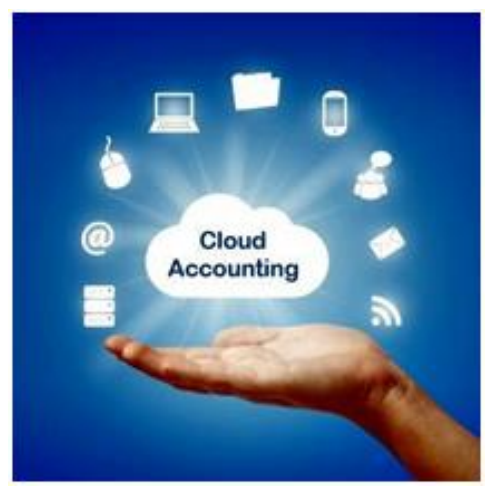




\section{FORMATS:}

Cloud accounting applications are typically offered in one of these two formats.

\section{Hosted application.}

Software as a service (Saas)

Benefits of Cloud Accounting:

Small businesses are the biggest beneficiaries of online cloud accounting and there are numerous ways in which moving to the cloud can be of value.

\section{FLEXIBLE:}

With a cloud based accounting solution you can access data from anywhere with an internet connection. If you use QuickBooks mobile accounting software then you can access all your work files from your mobile device, even if you're at home, on holiday or travelling to work. This gives you the freedom to work from wherever you want or need to; sending invoices and updating files on the move from your Smartphone or tablet.

\section{ECONOMIC:}

QuickBooks works on a subscription basis, so you only pay a monthly fee which can easily be recouped if you are charging your clients for access. Buying a permanent software solution outright would be far more expensive and the installation could lead to complications. By changing to a cloud based accounting solution, the firm of the future can quickly see increased profits.

\section{EFFICIENCY:}

The Firm of the Future is more efficient and earns more for less work. Instead of charging by the hour, you can charge your client according to a pricing plan which includes access to the cloud based accounting software you use. Fixed pricing plans change your client's attitude toward their accountant and the software made available to them. With cloud based accounting you only require one data file and it can be accessed remotely by you and your client. When you don't use a cloud based system it can be easy to make duplicate data files and update the wrong ones. This is not only confusing and time consuming, but can lead to embarrassing and costly mistakes. You save time and money through the efficiency of a cloud based accounting solution.

\section{ACCESS ANYWHERE, ANYTIME:}

With cloud accounting solutions, you don't have to be tied to the one desktop computer (out the back of the store). For example, MYOB Essentials, our web browser-based accounting solution, you can $\log$ in anywhere you've got a web browser. Or with MYOB Account Right, you can you can get the power of the desktop and convenience of the web; install MYOB Account Right on any desktop and sync up with your data from the internet. You can even use your smartphone with MYOB OnTheGo to get the critical information you need on iOS and Android from both Essentials and Account Right.

\section{Why Your Financial Data Is More Secure In Cloud}

\section{EASY, SECURE SHARING:}

You can share the data with as many others asyou like, whether it's your accountant, your bookkeeper, your business coach or even your bank manager. No longer is it necessary to email selected reports or the data file or - even less convenient - backing up the file to a USB stick and delivering or sending it to whoever needs the data.

\section{NO CAPITAL EXPENDITURE:}

The cost of cloud accounting software is paid monthly and hence no capital expenditure. This helps you to change the software's if you are not happy; also this reduces the risk of losing the Capex investment in case if business stops in the short run.

\section{SAVE TIME WITH AUTOMATION:}

Don't waste time posting and chasing invoices. Cloud accounting software automatically generates invoices - as well as reminders - at regular intervals, meaning you don't have to manually keep track of debtors. If you combine your accounting software with HR and Payroll applications you can also automatically generate pay slips and other HMRC documents.

\section{KEEPS YOUR INFORMATION SECURE:}

As your data is saved on a secure cloud server and is constantly backed up, you don't need to worry about your data being hacked or compromised. Even if your computer crashes, everything is still saved in the cloudSoftware is consistently updated and improved without you having to do anything Rather than having to wait for a new iteration of a programme, cloud 
accounting software is constantly updated by in-house developers. This means that if things change (e.g. auto-enrolment or the introduction of VAT MOSS), cloud software is agile enough to keep up-to-date in real time. In addition, unlike desktop accounting software programmes, these updates are free and included as part of your monthly subscription fee.

\section{WORK FROM ANYWHERE WITH AN INTERNET CONNECTION:}

Cloud accounting software means you no longer need to worry about maintaining spreadsheets or installing a programme on one machine. The cloud allows you to log in to your business's account anywhere with an internet connection. Once you sign up, you can get started straight away.

\section{REAL-TIME INFORMATION UPDATING:}

One of the common problems with traditional accounting systems involved updating accounting information. When one figure needed to be changed, it meant manually recording the change in each location where the figure appeared, including forms, ledgers, and other documents. With cloud accounting, when new data is entered, it populates each location where it's required. This saves time, money, and potential headaches that could arise if any locations are missed.

\section{TEAM-WIDE AVAILABILITY:}

Cloud accounting benefits entire business teams because the data is available to all authorized users at all times. It's easily scalable. Adding new users is simple_-just set up an authorized profile and password and you're ready to go. Even better, it makes collaboration easier. There's no more need to gather in one office and take turns to reviewing important documents. All authorized users with access to the internet can see accounting data simultaneously, from wherever they may be.

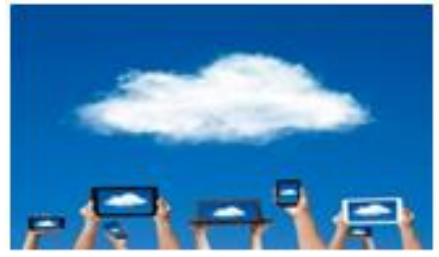

\section{CHALLENGES OF CLOUD ACCOUNTING: IDENTIFYING A CHAMPION:}

Identifying the leader within the firm that will champion this project is a hurdle many firms are finding difficult to overcome. Finding a leader with the influence within the firm and access to resources is an important first step.

\section{SHIFTING THE MINDSET:}

Many of the higher-value advisory services I've previously mentioned can jeopardize independence for the firm. Shifting from an assurance to an advisory mindset can be challenging for many firms. However, most are finding that the advisory services provide much more opportunities than the traditional audit work. To overcome this, several firms are setting up separate entities or referring the audit work to other CPA firms.

\section{BUILDING THE TEAM:}

To do this and do it right, dedicated resources are required. Many firms are struggling because they've assigned this as almost a second job to their teammembers. It's a chicken and the egg situation where firms want proof before fully committing resources to this endeavor. Yet it's hard to prove without the dedicated resources required.

\section{SERVICE LEVEL AGREEMENTS:}

The larger the business risk the more important it will be for suppliers and customers to understand what level of services can be relied upon. There is nothing about the cloud that makes this in principle different from any other outsourcing of services. However this will delay many large IT shops from embracing cloud suppliers as well as be a major source of FUD by cloud opponents.

\section{MANAGING CHANGE:}

Implementing change is always hard and making this switch - in software, mindset, process, etc. - is no different. Education and effective communication are essential to successfully navigating the change effort. A strong leader as the champion makes all the difference. Cloud accounting is transformational to our profession in the services we provide and the way we collaborate with clients. Regardless of whether you are just getting started or you've already built out a successful practice, there is still a huge opportunity and growing demand in the marketplace. This is a global movement and is frequently changing. You don't have to take the journey alone though as there is an abundance of information available - blogs, articles and training. There are also peer communities that can harness the wisdom of the crowd, hold you accountable and fast-track your progress. Take advantage of these resources to make sure your firm is 
knowledgeable and ready to capitalize on the REFERENCES:

opportunity.

\section{CONCLUSION:}

Cloud computing has become one of the transformational technologies that is tremendously important to improve ways of doing business. It has been proved to be a valuable asset for organizations to stay competitive. Cloud computing has been defined from different perspectives by different experts and it is difficult to discern exactly how cloud computing is constituted. As discussed in this paper, the main benefit is it helps to reduce the unnecessary costs such as purchasing and maintaining hardware and software. As discussed in this paper, cloud computing brings conveniences and benefits to the organizations such as business flexibility, cost reduction, automatic hardware and software upgrade, agility and scalability. The main benefit is it helps to reduce the unnecessary costs such as purchasing and maintaining hardware and software.
1. www.hawsons.co.uk/cloud-service-providers.

2. Future of Cloud Computing Survey, North Bridge Venture Partners, June 2011, http://www.slideshare.net/martinwalsh/the-futureofcloud-computing-2011

3. https://www.mcgrathnicol.com/.../ARITA_TheChallenges-of-Cloud-Accounting_Mar...Cached by P GOSNELL

\section{Author:}

Dave Thomas is cofounder/chairman of Bedarra Res www.Online-Learning.com and the Open Augment Consorti founding director of the Agile Alliance

(www.agilealliance.com). He is an adjunct research profess and the Queensland University of Technology, Australia. Da Object Technology International (www.oti.com) creator of Visual Age for Smalltalk, for Java, and Micro Edition for e dave@bedarra.com or www.davethomas.net. 